\title{
In Vitro and In Silico Characterization of Lemborexant (E2006), a Novel Dual Orexin Receptor Antagonist ${ }^{[}$
}

\author{
Carsten Theodor Beuckmann, Michiyuki Suzuki, Takashi Ueno, Kazuya Nagaoka, Tohru Arai, \\ and Hiroyuki Higashiyama
}

\begin{abstract}
Neurology Business Group, Discovery (C.T.B.), Drug Metabolism and Pharmacokinetics (T.U.), hhc Data Creation Center (K.N.), and Medicine Development Center (T.A.), Eisai Co., Ltd., Tsukuba, Ibaraki, Japan; and Global Regulatory Affairs (M.S.), Neurology Business Group (H.H.), Japan and Asia Clinical Development, Eisai Co., Ltd., Bunkyo, Tokyo, Japan
\end{abstract}

Received March 16, 2017; accepted May 23, 2017

\section{ABSTRACT}

Orexin (hypocretin) neuropeptides have, among others, been implicated in arousal/sleep control, and antagonizing the orexin signaling pathway has been previously demonstrated to promote sleep in animals and humans. This mechanism opens up a new therapeutic approach to curb excessive wakefulness in insomnia disorder rather than to promote sleep-related signaling. Here we describe the preclinical pharmacological in vitro and in silico characterization of lemborexant $((1 R, 2 S)-2-\{[(2,4-$ dimethylpyrimidin-5-yl)oxy]methyl\}-2-(3-fluorophenyl)- $N$-(5fluoropyridin-2-yl)cyclopropanecarboxamide)), a dual orexin receptor antagonist (DORA), as a novel experimental therapeutic agent for the symptomatic treatment of insomnia disorder and compare its properties to two other DORAs, almorexant and suvorexant. Lemborexant binds to both orexin receptors and functionally inhibits them in a competitive manner with low nanomolar potency, without any species difference apparent among human, rat, and mouse receptors. Binding and dissociation kinetics on both orexin receptors are rapid. Lemborexant is selective for both orexin receptors over 88 other receptors, transporters, and ion channels of important physiologic function. In silico modeling of lemborexant into the orexin receptors showed that it assumes the same type of conformation within the receptor-binding pocket as suvorexant, the $\pi$-stacked horseshoe-like conformation.

\section{Introduction}

Insomnia disorder is a major problem in our societies, causing substantial individual and social burden. The majority of sleep medications enforce sleep-promoting signaling pathways, although recent neuroimaging evidence suggests that insomnia should be seen as inappropriate wakefulness or arousal at habitual bedtime rather than an inability to sleep (Nofzinger, 2004; Nofzinger et al., 2004).

This research was supported by Eisai Co., Ltd.

Part of the data in this manuscript has been presented previously at the following meetings:

Beuckmann CT, Suzuki M, Nakagawa M, Akasofu S, Ueno T, Arai T, Higashiyama H (2014) Preclinical Pharmacological Characterization Of E2006, A Novel Dual Orexin Receptor Antagonist For Insomnia Treatment. (The 39th Annual Meeting of the Japanese Society of Sleep Research; July 3-4, 2014, Tokushima City, Tokushima, Japan); Beuckmann CT, Suzuki M, Nakagawa M, Akasofu S, Ueno T, Arai T, Higashiyama H (2016) Preclinical Pharmacological Characterization Of Lemborexant, A Novel Dual Orexin Receptor Antagonist For Insomnia Treatment. (The 4th Annual International Institute for Integrated Sleep Medicine Symposium, February 26, 2016, Tsukuba, Ibaraki, Japan).

https://doi.org/10.1124/jpet.117.241422

S This article has supplemental material available at jpet.aspetjournals.org.
Since the simultaneous discovery of the orexin (also known as hypocretin) neuropeptide signaling system by two research groups (De Lecea et al., 1998; Sakurai et al., 1998), it has become clear that this system is involved in many physiologic functions, among them sleep/wake control (Chemelli et al., 1999), feeding (Sakurai et al., 1998), energy homeostasis (Hara et al., 2001; Yamanaka et al., 2003), and reward seeking (Boutrel et al., 2005; Harris et al., 2005), to name the most prominent ones.

The two neuropeptides, orexin-A (OXA) and orexin-B (OXB), are derived from the common precursor prepro-orexin and activate the postsynaptically localized orexin-1 receptor (OX1R) and orexin-2 receptor (OX2R). OXA has similar affinity for both OX1R and OX2R, whereas OXB has higher preference for OX2R (Sakurai et al., 1998). Orexin-expressing neurons in the central nervous system are confined to the hypothalamus (De Lecea et al., 1998; Sakurai et al., 1998) from which they project to numerous wake-controlling nuclei such as the noradrenergic locus coeruleus, the serotonergic dorsal raphe nucleus, the cholinergic laterodorsal/pedunclopontine tegmental nuclei, and the histaminergic tuberomamillary nucleus

ABBREVIATIONS: $\mathrm{B}_{\max }$, maximum binding; $\mathrm{CHO}$, Chinese hamster ovary; DORA, dual orexin receptor antagonist; E2006, (1R,2S)-2-\{[(2,4dimethylpyrimidin-5-yl)oxy]methyl\}-2-(3-fluorophenyl)- $N$-(5-fluoropyridin-2-yl)cyclopropanecarboxamide); EMPA, $N$-ethyl-2-[(6-methoxy-3-pyridinyl) [(2-methylphenyl)sulfonyl]amino]-N-(3-pyridinylmethyl)-acetamide; FDSS, Functional Drug Screening System; HEK293, human embryonic kidney 293; hOX1R, human orexin-1 receptor; hOX2R, human orexin-2 receptor; hOXB, human orexin-B; $\mathrm{K}_{\mathrm{i}}$, Inhibition constant; $\mathrm{k}_{\text {off }}$, dissociation rate constant; $\mathrm{k}_{\mathrm{on}}$, association rate constant; MD, molecular dynamics; MM-GBSA, molecular mechanics generalized born surface area; mOX2R, mouse orexin-2 receptor; mOXB, mouse orexin-B; MT1R, melatonin-1 receptor; MT2R, melatonin-2 receptor; OX1R, orexin-1 receptor; OX2R, orexin-2 receptor; OXA, orexin-A; OXB, orexin-B; OXR, orexin receptor; PDB, Protein Data Bank; PLAP, placental alkaline phosphatase; RBA, receptor binding assay; REM, rapid eye movement; 2-SORA, orexin-2 receptor-selective antagonist. 
(for review, see Sakurai, 2007), all of which contain neurons expressing OX1R, OX2R, or both. Regarding the role of both orexin receptors (OXRs) in sleep/wake regulation, it seems that OX1R is suppressing the onset of rapid eye movement (REM) sleep, whereas the OX2R is mostly responsible for suppressing non-REM sleep onset and is also involved in REM sleep control to a certain extent (Willie et al., 2003).

The discovery that orexins are involved in sleep/wake regulation (Chemelli et al., 1999; Lin et al., 1999) triggered efforts by pharmaceutical companies to develop OXR antagonists for treating insomnia, which is believed to be inappropriately timed hyperarousal or wakefulness, rather than the inability of the brain to sleep (Nofzinger, 2004; Nofzinger et al., 2004). Rather than supporting sleep-promoting circuits, inhibiting the wake-promoting orexin signaling pathway offers a novel therapeutic approach to dampen the excessive wakefulness in insomnia. Preclinical and clinical evaluation of DORAs included almorexant (Fig. 1B), which was discontinued in clinical phase 3 (Brisbare-Roch et al., 2007); SB-649868 (Bettica et al., 2012a,b) and filorexant (Winrow et al., 2012), which both completed clinical phase 2; and suvorexant (Fig. 1C), which was approved in the United States and Japan for treatment of insomnia (Cox et al., 2010; Winrow et al., 2011; Herring et al., 2012). Recently, two OX2R-selective antagonists (2-SORAs), MK-1064 (Roecker et al., 2014; Gotter et al., 2016) and JNJ-42847922 (Bonaventure et al., 2015), have been introduced into clinical testing and achieved proof-of-activity in healthy subjects.

We have previously disclosed the DORA lemborexant [E2006: $(1 R, 2 S)-2-\{[(2,4$-dimethylpyrimidin-5-yl)oxy]methyl $\}$ 2-(3-fluorophenyl)- $N$-(5-fluoropyridin-2-yl)cyclopropane carboxamide)] (Yoshida et al., 2015) (Fig. 1A), which is currently in phase 3 clinical development for treatment of insomnia disorder. Its medicinal chemistry evolution and initial pharmacological evaluation have already been reported (Yoshida et al., 2014, 2015). Here we describe in more detail the preclinical pharmacological in vitro and the in silico characterization of lemborexant.

\section{Materials and Methods}

\section{Chemical Compounds}

DORAs lemborexant, almorexant, and suvorexant have been synthesized in-house, and concentrations indicate free bases. $\left[{ }^{125} \mathrm{I}\right] \mathrm{OXA}$ was purchased from PerkinElmer (Waltham, MA), $\left[{ }^{3} \mathrm{H}\right] N$-ethyl-2-[(6methoxy-3-pyridinyl)[(2-methylphenyl)sulfonyl]amino]- $N$-(3-pyridinylmethyl)acetamide (EMPA) was purchased from Sekisui Medical (Tokyo, Japan), and unlabeled EMPA and SB-334867 were purchased from Tocris Bioscience (Bristol, UK).

\section{Measurement of Affinity by Receptor Binding Assay}

The binding affinity was assayed by receptor binding assay (RBA) using a 96 -well Flashplate (PerkinElmer). The membrane fraction was prepared from Chinese Hamster Ovary (CHO) cells expressing human OX1R (hOX1R) or human OX2R (hOX2R). Membrane suspension of hOX1R or hOX2R ( $5 \mu \mathrm{g}$ protein/assay) was mixed with test antagonists [lemborexant $(0.6-200 \mathrm{nmol} / \mathrm{l})$, almorexant $(0.2-200 \mathrm{nmol} / \mathrm{l})$, or suvorexant $(0.2-60 \mathrm{nmol} / \mathrm{l})]$, as well as OXA (10 $\mu \mathrm{mol} / 1$; Peptide Institute, Osaka, Japan) solution or vehicle and $\left[{ }^{125} \mathrm{I}\right] \mathrm{OXA}$ solution $(0.2 \mathrm{nmol} / \mathrm{l}$; PerkinElmer). The mixtures (final volume, $100 \mu \mathrm{l}$ ) were incubated for 30 minutes at room temperature on a 96 -well Flashplate. All reaction mixtures were discarded, followed by two washing steps with $200 \mu \mathrm{l}$ of $25 \mathrm{mmol} / \mathrm{l} \mathrm{HEPES}$ buffer containing $525 \mathrm{mmol} / \mathrm{l} \mathrm{NaCl}$. The remaining radioactivity (in $\mathrm{dpm}$ ) of each well was measured by TopCount (PerkinElmer), and inhibitory activity of the test antagonist was calculated using the following formula:

$$
\text { Inhibition } \%=100-100 \times(\mathrm{T}-\mathrm{N}) /(\mathrm{C}-\mathrm{N})
$$

where $\mathrm{T}$ is reported in $\mathrm{dpm}$ in the presence of test antagonist (test), $\mathrm{N}$ is reported in $\mathrm{dpm}$ in the presence of $10 \mu \mathrm{mol} / \mathrm{l}$ OXA (nonspecific binding), and $\mathrm{C}$ is reported in $\mathrm{dpm}$ in the absence of compound (control).

Values in experiments were determined in triplicate (lemborexant, almorexant) or quadruplicate (suvorexant). Experiments with lemborexant were conducted three times in an identical fashion, and $\mathrm{IC}_{50}$ values were calculated for each experiment before averaging for the final $\mathrm{IC}_{50}$ value and its S.E.M. The experiments for almorexant and suvorexant were conducted once, with each value expressed as the mean \pm S.E.M. for statistical analysis.

In all experiments, the mean $\mathrm{IC}_{50}$ value and S.E.M. were calculated based on the sigmoidal curves of inhibitory activity (normalized response in percentage) versus the respective antagonist concentration (using least-squares fit without constraints and with variable slope). Statistical analyses were performed using GraphPad Prism version 6.02 (GraphPad Software, La Jolla, CA).

\section{Cell-Based Calcium Mobilization Assay upon Functional OXR Activation}

Measurements of intracellular calcium mobilization upon functional activation of recombinantly expressed OX1Rs and OX2Rs of human, rat, and mouse origin in human embryonic kidney 293 (HEK293) cells by the addition of OXA (at approximately $\mathrm{EC}_{50}$ ), and the antagonistic effect on this activation by test compounds was performed as described previously (Marlo et al., 2009; Yoshida et al., 2015) using the Functional Drug Screening System (FDSS) 6000 (Hamamatsu Photonics, Hamamatsu, Japan). Experiments were conducted independently three times with quadruplicate values, and $\mathrm{IC}_{50}$ as well as inhibition constant $\left(K_{\mathrm{i}}\right)$ values were calculated (using a least-squares fit without constraints and with variable slope in four parameters) from each independent experiment before averaging for the final result. Analysis was performed using GraphPad Prism (version 6.07; GraphPad Software).

\section{Cell-Based Functional Reporter Enzyme Assay}

HEK293 cells were stably transfected with human or mouse OX1R or OX2R and with a reporter system (Chen et al., 1995; Durocher et al., 2000) where a reporter enzyme [placental alkaline phosphatase (PLAP)] (Goto et al.,1996) could be induced upon functional OXR activation through an intracellular $\mathrm{Ca}^{2+}$-dependent reporter unit.

Cells were seeded into 96 -well plates at a density of 10,000/well and cultivated overnight in culture medium. Next day, $5 \mu \mathrm{l}$ of lemborexant solutions were added to cultured cells in 96-well plates to a final culture medium volume of $115 \mu \mathrm{l}$ (23-fold dilution), resulting in 1,3 , $10,30,100,300$, and $1000 \mathrm{nmol} / /$ end concentrations for the incubation of cells.

After the addition of lemborexant and incubation for approximately 2-3 hours at room temperature, orexin peptide agonists human/mouse OXA (Peptide Institute), human OXB (hOXB; Peptide Institute), mouse OXB (mOXB; Peptide Institute), or modified [Ala ${ }^{11}, \mathrm{D}_{\mathrm{Leu}}{ }^{15}$ ]OXB (Tocris Bioscience) were diluted in Dulbecco's modified Eagle's medium (containing $0.1 \%$ bovine serum albumin and $3.45 \mu \mathrm{mol} / \mathrm{l}$ forskolin), and $10 \mu \mathrm{l}$ was added to cell wells, resulting in a $115-\mu \mathrm{l}$ final volume. Final concentrations of peptide agonists ranged from 0.01 to $1000 \mathrm{nmol} / \mathrm{l}$. After mixing by agitation of the plates, cells were incubated at $37^{\circ} \mathrm{C}$ for about 20 hours, with each respective concentration combination of lemborexant and peptide agonist having been applied to four cell wells. There are two amino acids different between hOXB and mOXB. For this reason, hOX2R was activated with hOXB, 

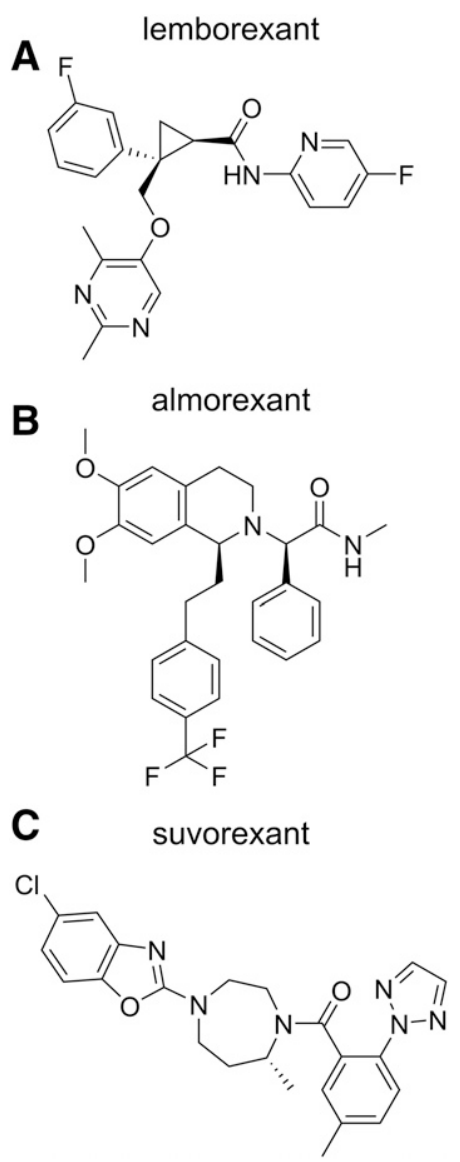

Fig. 1. Chemical structures of lemborexant, almorexant, and suvorexant.

and mouse OX2R (mOX2R) was activated with mOXB. [Ala ${ }^{11}$ D-Leu ${ }^{15}$ ]-OXB has been described to be of higher selectivity for OX2R than natural OXB (Asahi et al., 2003).

Next day, $5 \mu$ l of cell supernatant was transferred from each cell well to 384-well plates and mixed with $20 \mu \mathrm{l}$ of detection buffer and $25 \mu \mathrm{l}$ of Lumi-Phos 530 reagent (Wako, Osaka, Japan). After incubation at room temperature under light protection for 2 hours, receptor activation was determined via the luminescence intensity measurement of secreted PLAP activity using a Fusion $\alpha$-FP HT device (PerkinElmer). PLAP activity of every cell well was determined as a single data point, and values of four identical cell wells were averaged for analysis.

To assess cell viability after the removal of $5 \mu \mathrm{l}$ of cell supernatant for PLAP activity measurements, $10 \mu \mathrm{l}$ of alamarBlue reagent (BioSource, Camarillo, CA) was added to the cell-containing 96-well plates, mixed by agitation of plates, and incubated for 2-3 hours at $37^{\circ} \mathrm{C}$, after which fluorescence intensity was measured using a Fusion $\alpha$-FP HT device (PerkinElmer) (excitation wavelength, $535 \mathrm{~nm}$; emission wavelength, $590 \mathrm{~nm}$ ). The viability value of every cell well was determined as a single data point. Quadruplicate measurements of luminescence were averaged and plotted as the mean. Analysis was performed using nonlinear regression and the Gaddum/Schild EC $_{50}$ shift method using GraphPad Prism (version 5.02; GraphPad Software). Parameters calculated were $K_{\mathrm{i}}$ values and Schild slopes.

\section{Kinetic RBA on hOX1R}

Determination of Association Rate Constant and Dissociation Rate Constant of $\left.{ }^{\left[{ }^{125}\right.} \mathbf{I}\right]$ OXA. The methodology described here is based on Dowling and Charlton (2006) and Motulsky and Mahan (1984). $\left[{ }^{125} \mathrm{I}\right] \mathrm{OXA}$ (PerkinElmer) at $0.2 \mathrm{nmol} / /$ final concentration was incubated with membranes of hOX1R-expressing CHO cells $(20 \mu \mathrm{g}$ protein) at $22^{\circ} \mathrm{C}$ to measure the association with rate [association rate constant $\left(\mathrm{k}_{\mathrm{on}}\right)$ ]. Nonspecific binding was measured with OX1Rselective antagonist SB-334867 ( $1 \mu \mathrm{mol} / \mathrm{l}$; Tocris Bioscience) for each incubation time point.

The dissociation was initiated by the addition of an excess of SB-334867 $(1 \mu \mathrm{mol} / \mathrm{l})$ after 90 minutes of incubation of $\left[{ }^{125} \mathrm{I}\right] \mathrm{OXA}$ $(0.2 \mathrm{nmol} / \mathrm{l})$ with the hOX1R-containing $\mathrm{CHO}$ cell membranes, and the time course of signal decrease was measured. The experiment was performed once in triplicate $(n=3)$. All reaction mixtures were filtered rapidly under vacuum through glass fiber filters (GF/B; PerkinElmer) presoaked with $0.3 \%$ polyethylenimine and rinsed several times with an ice-cold buffer $(50 \mathrm{mmol} / \mathrm{l}$ Tris- $\mathrm{HCl} / 150 \mathrm{mmol} / \mathrm{l} \mathrm{NaCl})$ using a 96-sample cell harvester (UniFilter; PerkinElmer). After drying, radioactivity on filters was measured in a scintillation counter (TopCount; PerkinElmer) as cpm using a scintillation cocktail (Microscint 0; PerkinElmer). Data were analyzed using GraphPad Prism software, where the $\mathrm{k}_{\text {on }}$ value of $\left[{ }^{125} \mathrm{I}\right] \mathrm{OXA}$ was calculated by fitting to the following formula:

$$
\mathrm{Y}=\operatorname{Ymax} \times\left(1-\exp \left(-\mathrm{k}_{\mathrm{ob}} \times \mathrm{X}\right)\right)
$$

where $\mathrm{Y}$ is binding (in cpm), $\mathrm{X}$ is incubation time, Ymax is the maximum binding $\left(\mathrm{B}_{\max }\right)$ observed, and $\mathrm{k}_{\mathrm{ob}}$ is $\mathrm{k}_{\mathrm{on}} \times$ radioligand concentration $+\mathrm{k}_{\text {off }}$ (dissociation rate constant).

The $\mathrm{k}_{\text {off }}$ value of $\left[{ }^{125} \mathrm{I}\right] \mathrm{OXA}$ was calculated by fitting to the following formula:

$$
\mathrm{Y}=(\mathrm{Y} 0-\mathrm{NS}) \times \exp \left(-\mathrm{k}_{\mathrm{off}} \times \mathrm{X}\right)+\mathrm{NS}
$$

where $\mathrm{Y}$ is binding (in cpm), $\mathrm{X}$ is incubation time, $\mathrm{Y} 0$ is binding at time zero, and NS is binding (nonspecific) at infinite times.

Determination of $\mathbf{k}_{\mathrm{on}}, \mathbf{k}_{\mathrm{off}}$, and Dissociation Half-Life of Lemborexant. The association kinetics of the radioligand $\left[{ }^{125} \mathrm{I}\right] \mathrm{OXA}$ were measured as described above in the absence and presence of 7 , 14 , and $28 \mathrm{nmol} / \mathrm{l}$ unlabeled lemborexant in the same experiment. Three independent experiments were performed, with values being determined in triplicate $(n=3)$.

The results were analyzed as follows. The harmonic mean of the $\mathrm{k}_{\text {off }}$ values of the radioligand $\left[{ }^{125} \mathrm{I}\right] \mathrm{OXA}$ obtained in the three dissociation experiments was calculated and then used as a fixed constant (K2) for the analysis of the association experiments. The three association experiments were first analyzed individually. The $\mathrm{k}_{\text {on }}$ and $\mathrm{B}_{\max }$ values of $\left[{ }^{125} \mathrm{I}\right] \mathrm{OXA}$ were determined individually for each of the three association experiments. The $\mathrm{k}_{\text {on }}$ (K3) and $\mathrm{k}_{\text {off }}(\mathrm{K} 4)$ values of the unlabeled lemborexant were calculated individually from the results of each of the three association experiments, using the corresponding individual $\left[{ }^{125} \mathrm{I}\right] \mathrm{OXA} \mathrm{k}_{\mathrm{on}}(\mathrm{K} 1)$ and $\mathrm{B}_{\max }$ values and the harmonic mean of the $\left[{ }^{125} \mathrm{I}\right] \mathrm{OXA} \mathrm{k}_{\text {off }}$ values (K2) of the three dissociation experiments. Finally, the harmonic means of the $\mathrm{k}_{\text {on }}$ and $\mathrm{k}_{\text {off }}$ values, and the arithmetic means of the dissociation half-lives, respectively, were calculated from the values of the three individual experiments.

Data were analyzed using GraphPad Prism software (version 6.07; GraphPad Software), where the $\mathrm{k}_{\text {on }}$ and $\mathrm{k}_{\text {off }}$ values of lemborexant were calculated by fitting to the following formula:

$$
\begin{aligned}
\mathrm{Y}= & \mathrm{Q} \times(\mathrm{K} 4 \times \mathrm{DIFF} /(\mathrm{KF} \times \mathrm{KS})+((\mathrm{K} 4-\mathrm{KF}) / \mathrm{KF}) \\
& \times \exp (-\mathrm{KF} \times \mathrm{X})-((\mathrm{K} 4-\mathrm{KS}) / \mathrm{KS}) \times \exp (-\mathrm{KS} \times \mathrm{X}))
\end{aligned}
$$

where $\mathrm{Y}$ is specific binding (in cpm), $\mathrm{X}$ is time, $\mathrm{KA}=\mathrm{K} 1 \times \mathrm{L} \times 10^{-9}+$ $\mathrm{K} 2, \mathrm{~KB}=\mathrm{K} 3 \times \mathrm{I} \times 10^{-9}+\mathrm{K} 4, \mathrm{~S}=\mathrm{SQRT}\left((\mathrm{KA}-\mathrm{KB})^{2}+4 \times \mathrm{K} 1 \times \mathrm{K} 3 \times\right.$ $\left.\mathrm{L} \times \mathrm{I} \times 10^{-18}\right), \mathrm{KF}=0.5 \times(\mathrm{KA}+\mathrm{KB}+\mathrm{S}), \mathrm{KS}=0.5 \times(\mathrm{KA}+\mathrm{KB}-\mathrm{S})$, $\mathrm{DIFF}=\mathrm{KF}-\mathrm{KS}, \mathrm{Q}=\mathrm{B}_{\max } \times \mathrm{K} 1 \times \mathrm{L} \times 10^{-9} / \mathrm{DIFF}, \mathrm{L}$ is the concentration of $\left[{ }^{125} \mathrm{I}\right] \mathrm{OXA}$ (in nmol/l), $\mathrm{K} 1=\mathrm{k}_{\mathrm{on}}\left[{ }^{125} \mathrm{I}\right] \mathrm{OXA}, \mathrm{K} 2=\mathrm{k}_{\mathrm{off}}$ $\left[{ }^{125} \mathrm{I}\right] \mathrm{OXA} \mathrm{K} 3=\mathrm{k}_{\mathrm{on}}$ lemborexant, $\mathrm{K} 4=\mathrm{k}_{\text {off }}$ lemborexant, half-life equals the $\ln (2)$ value divided by $\mathrm{k}_{\text {off }}$, and $\mathrm{I}$ is the concentration of the inhibitor.

The S.E.M. values of $\mathrm{k}_{\mathrm{on}}$ and $\mathrm{k}_{\text {off }}$ were calculated using SAS software (version 8.03; SAS Institute, Inc., Cary, NC), whereas S.E.M. values 
for half-lives were calculated using GraphPad Prism (version 6.07; GraphPad Software).

\section{Kinetic RBA on hOX2R}

Determination of $\mathbf{k}_{\text {off }}$ of $\left[{ }^{3} \mathbf{H}\right]$ EMPA. The $\mathbf{k}_{\text {off }}$ value of $\left[{ }^{3} \mathrm{H}\right]$ EMPA was determined by allowing $\left[{ }^{3} \mathrm{H}\right]$ EMPA to reach equilibrium with hOX2R expressed in CHO cell membranes. After equilibrium was reached at 2 hours, the reassociation of $\left[{ }^{3} \mathrm{H}\right]$ EMPA was prevented by adding an excessive amount of EMPA. Bound $\left[{ }^{3} \mathrm{H}\right] \mathrm{EMPA}$ was then measured at multiple time points over 90 minutes.

Membrane suspension of hOX2R (final $0.8 \mu \mathrm{g}$ protein/assay) and $\left[{ }^{3} \mathrm{H}\right] \mathrm{EMPA}$ (final $3 \mathrm{nmol} / \mathrm{l}$ ) were mixed, and the mixture $(180 \mu \mathrm{l})$ was incubated for 2 hours at room temperature on a 96 -well nonbinding surface plate (Corning, Corning, NY). Then, $20 \mu \mathrm{l}$ of EMPA solution $(100 \mu \mathrm{mol} / \mathrm{l})$ was added and incubated at room temperature for between 5 and 90 minutes. For the 0 minute value, assay buffer instead of EMPA solution was added. All reaction mixtures were filtrated with UniFilter-96 GF/C (PerkinElmer) and washed twice with assay buffer containing $500 \mathrm{mmol} / \mathrm{l} \mathrm{NaCl}$ using MicroBeta FilterMate-96 Harvester (PerkinElmer). UniFilter-96 was dried, and $50 \mu \mathrm{l}$ of Micro Scint 20 (PerkinElmer) was added to each well. The radioactivity of each well was measured by TopCount (PerkinElmer).

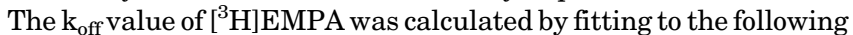
formula:

$$
\mathrm{Y}=(\mathrm{Y} 0-\mathrm{NS}) \times \exp \left(-\mathrm{k}_{\mathrm{off}} \times \mathrm{X}\right)+\mathrm{NS}
$$

where $\mathrm{Y}$ is binding (in cpm), $\mathrm{X}$ is incubation time, $\mathrm{Y} 0$ is binding at time zero, NS is binding (nonspecific) at infinite times, and the half-life equals the $\ln (2)$ value divided by $\mathrm{k}_{\text {off }}$.

GraphPad Prism version 6.02 (GraphPad Software) was used for the calculation. Each data point was measured in triplicate, and the experiment was repeated three times.

Determination of $k_{\text {on }}$ of $\left[{ }^{3} H\right]$ EMPA and $k_{\text {on }}$ and $k_{o f f}$ of Lemborexant, Suvorexant, and Almorexant. $\left[{ }^{3} \mathrm{H}\right]$ EMPA was added simultaneously with several concentrations of test antagonist (lemborexant, suvorexant, or almorexant) to hOX2R-expressing CHO cell membranes. The degree of $\left[{ }^{3} \mathrm{H}\right] \mathrm{EMPA}$ bound to receptor was assessed at multiple time points over 4-6 hours after the addition of $\left[{ }^{3} \mathrm{H}\right] \mathrm{EMPA}$ and a test antagonist mixture (Dowling and Charlton, 2006).

Membrane suspension (final $0.8 \mu \mathrm{g}$ protein/assay), $\left[{ }^{3} \mathrm{H}\right] \mathrm{EMPA}$ (final $3 \mathrm{nmol} / \mathrm{l})$, and test antagonist $(0,1,3$, or $10 \mathrm{nmol} / \mathrm{l})$ were mixed at room temperature for 0.5-240 minutes (lemborexant and suvorexant) or 0.5-360 minutes (almorexant). For the determination of nonspecific binding, $\left[{ }^{3} \mathrm{H}\right] \mathrm{EMPA}$ (final $3 \mathrm{nmol} / \mathrm{l}$ ), test antagonist (final $20 \mu \mathrm{mol} / \mathrm{l}$ ), and membrane suspension (final $0.8 \mu \mathrm{g}$ protein/assay) were mixed and incubated for 4 hours (lemborexant and suvorexant) or 6 hours (almorexant) at room temperature. All reaction mixtures were filtrated with UniFilter-96 GF/C and washed twice with the assay buffer containing $500 \mathrm{mmol} / \mathrm{l} \mathrm{NaCl}$ using MicroBeta FilterMate-96 Harvester. UniFilter-96 was dried, and $50 \mu \mathrm{l}$ of Micro Scint 20 was added to each well. The radioactivity (in cpm) of each well was measured by TopCount (PerkinElmer).

The $\mathrm{k}_{\mathrm{on}}$ and $\mathrm{k}_{\mathrm{off}}$ values of lemborexant were calculated as described previously (Mould et al., 2014), using the $\mathrm{k}_{\text {on }}$ and $\mathrm{k}_{\text {off }}$ values of $\left[{ }^{3} \mathrm{H}\right]$ EMPA (calculated with Phoenix WinNonlin version 6.3; Certara, Princeton, NJ).

Each value is expressed as the mean and S.E.M. The mean value and S.E.M. were calculated based on the $\mathrm{k}_{\text {on }}$ or $\mathrm{k}_{\text {off }}$ values from three independent experiments in triplicate (EMPA and lemborexant) or triplicate measurements of one experiment (almorexant and suvorexant)

\section{Off-Target Panel Binding Assay}

A panel binding/functional assay was conducted on 80 receptors, transporters, and ion channels of important physiologic function
(High-Throughput Profile; CEREP, Celle l'Evescault, France), as well as eight additional drug dependence liability-related and sleep/wake regulation-related targets (CEREP), as listed in Supplemental Table 1. Lemborexant was tested in two concentrations (1 and $10 \mu \mathrm{mol} / \mathrm{l}$ ), and values were determined in duplicate. Binding was calculated as the percentage of inhibition of the binding of a radioactively labeled ligand specific for each target. Significant binding was defined as more than 50\% inhibition.

\section{Off-Target Functional Assay on Human Melatonin 1 Receptor and Human Melatonin 2 Receptor}

Human melatonin 1 receptor (MT1R) was stably expressed in HEK293 cells containing Gqi5 chimeric G-protein (MT1R + Gqi5/HEK293), which converts $\mathrm{G}_{\mathrm{i}}$-protein signaling from MT1R into intracellular calcium mobilization (Coward et al., 1998). Cells containing Gqi5 but no MT1R were used as control (Gqi5/HEK293). The same procedure was followed for cells expressing human melatonin 2 receptor (MT2R). Cell-based calcium mobilization functional assay was carried out as described above for OXRs. Each data point was measured in quadruplicate, and each experiment was performed three times.

\section{Population Patch-Clamp Study on Human $\mathrm{GABA}_{\mathrm{A}}$ Receptor}

Functional GABA A $_{A}$ receptor was stably expressed in HEK293 cells, which had been cotransfected via electroporation (microporator device) with three separate expression plasmids containing respective human subunits $\alpha 1, \beta 3$, and $\gamma 2$. Cells expressing human $\mathrm{GABA}_{\mathrm{A}}$ receptor $(\alpha 1, \beta 3, \gamma 2)$ were harvested via trypsinization and resuspended in Dulbecco's phosphate-buffered saline at a density of $2 \times 10^{6}$ cells $/ \mathrm{ml}$. Chloride ion current through the $\mathrm{GABA}_{\mathrm{A}}$ receptor was measured by population patch clamping of cells (Hollands et al., 2009 ) in the presence of the positive allosteric modulator GABA on an IonWorks Quattro Instrument (Molecular Devices, Sunnyvale, CA). Forty microliters of cell suspension was placed into the wells of PatchPlate PPC (Molecular Devices). After allowing cells to seal to the substrate and achieving a stable patch-clamp configuration, a voltage $\operatorname{ramp}(300 \mathrm{~ms},-80$ to $+60 \mathrm{mV})$ was applied, and the resulting currents were sampled at $2.5 \mathrm{kHz}$. After this initial signal measurement without GABA, $20 \mu \mathrm{l}$ of compound solution containing $0.9 \mu \mathrm{mol} / \mathrm{l}$ GABA and 3-fold concentrated compounds lemborexant or phenobarbital were added, and the same voltage ramp was applied again. Final concentrations for lemborexant or phenobarbital were $0.2,1$, and $5 \mu \mathrm{mol} / \mathrm{l}$, or 50 and $100 \mu \mathrm{mol} / \mathrm{l}$, respectively.

The influence of test compounds was measured as changes in the chloride ion current, with all electrophysiological measurements being conducted at room temperature. Phenobarbital at 50 and $100 \mu \mathrm{mol} / \mathrm{l}$ served as the positive control (reference compound). For data analysis, differences in currents at $0 \mathrm{mV}$ voltage before and after GABA and compound addition were used. Each data point was measured in quadruplicate, and the experiment was performed once.

\section{Computational Method for Complex Modeling and Energy Calculation of Lemborexant in hOX1R and hOX2R}

Lemborexant was docked into the X-ray crystal structures of hOX1R [Protein Data Bank (PDB) identifier 4ZJ8; Yin et al., 2016] and hOX2R (PDB identifier 4S0V; Yin et al., 2015) after the elimination of fusion protein and protein modeling using the Homology Modeling tool in MOE 2014.09 (Chemical Computing Group, Montreal, Canada) and Protein Preparation Wizard in Maestro (version 10.7; Schrödinger, New York, NY) with default settings.

Ligand docking simulations were conducted using Glide XP (version 7.2; Schrödinger) (Friesner et al., 2004; Halgren et al., 2004) after conformational search by MacroModel (version 11.3; Schrödinger). The binding poses were chosen by the clustering of ligand conformation and WaterMap/Molecular Mechanics Generalized Born Surface Area (MM-GBSA) scoring using WaterMap (version 2.8; Schrödinger). 
After ligand-protein complex modeling, molecular dynamics (MD) simulations were performed using Desmond (version 4.7 Schrödinger) (Abel et al., 2008). Each lemborexant-human OXR complex model was then embedded in a 1-palmitoyl-2-oleoylphosphatidylcholine lipid bilayer and solvated using a TIP3P box water model with $0.15 \mathrm{M} \mathrm{NaCl}$.

Binding free energy of representative complex structures from MD simulation trajectory were calculated by MM-GBSA technology (Huang et al., 2006; Lyne et al., 2006) using Prime MM-GBSA (version $3.0 ;$ Schrödinger)

\section{Results}

Binding Affinities and Antagonistic Activities of Lemborexant. The affinities for hOX2R and hOX1R were determined via RBA by the ability to inhibit binding of $\left[{ }^{125} \mathrm{I}\right]$ OXA to cell membranes prepared from either recombinant hOX1R- or hOX2R-expressing cells. Inhibition curves of radiolabeled tracer in the presence of lemborexant, almorexant, and suvorexant are depicted in Supplemental Fig. 1.

In addition, we evaluated the antagonistic function of OXR antagonists on recombinantly expressed hOX1Rs and hOX2Rs, of which activation by OXA triggers an intracellular calcium signal increase. To investigate whether species differences exist, antagonists were evaluated on OXRs of human, rat, and mouse origin. Antagonist inhibition curves for lemborexant, almorexant, and suvorexant as determined via direct calcium mobilization upon receptor activation by OXA are depicted in Supplemental Fig. 2.

Concentrations necessary for $\mathrm{IC}_{50}$ (via RBA) and $K_{\mathrm{i}}$ (via cellbased direct calcium imaging) values for the three DORAs were derived from data shown in Supplemental Figs. 1 and 2 and are listed in Table 1. Although lemborexant and almorexant would be categorized as a DORAs in the RBA as well as even more in the functional assay, both compounds have higher affinity for the OX2R than for the OX1R. In contrast, suvorexant showed a slightly higher preference for the OX1R in our assay system. Furthermore, we could not detect any substantial difference in OXR affinities of the three DORAs among the three species evaluated.

Binding Mode and Site. To determine binding mode and site, another cell-based functional assay was conducted that measured the activity of reporter enzyme PLAP. This enzyme was expressed and released into cell medium in relation to the intracellular $\mathrm{Ca}^{2+}$ increase upon OXR activation and was therefore a direct measure of OXR activation. In this assay, lemborexant did not show any agonistic activity on human or murine OXRs or any influence on cell viability up to $1 \mu \mathrm{mol} / \mathrm{l}$ (data not shown). The activation curves of human and murine OX1R by OXA and OX2R by three different peptide agonists and the dextral shift caused by titration with lemborexant are shown in Supplemental Fig. 3.

Data extracted from the curves in Supplemental Fig. 3 are listed in Table 2. Also in this assay, no species difference between human and murine OXRs could be found, and lemborexant showed higher affinity for OX2R than for OX1R. Schild slopes very close to a value of 1 indicate simple, competitive binding, and the fact that the compound shows comparable behavior against three different peptide agonists on the OX2Rs strongly suggests an orthosteric binding mode to the peptide binding pocket within the receptor. For the OX1R, only one peptide, OXA, was available as agonist; therefore, such a comparison could not be made.

Association and Dissociation Kinetics on Human OXRs. Association rates to and dissociation rates from the receptors were determined on the hOX1R for lemborexant and on the hOX2R for lemborexant, almorexant, and suvorexant via a kinetic RBA. For this purpose, surrogate radiolabeled tracers, DORA $\left[{ }^{125} \mathrm{I}\right] \mathrm{OXA}$ for hOX1R and 2-SORA $\left[{ }^{3} \mathrm{H}\right] \mathrm{EMPA}$ for hOX2R, were used. Dissociation characteristics of the labeled tracer molecules $\left[{ }^{125} \mathrm{I}\right] \mathrm{OXA}$ (Supplemental Fig. 4A) and $\left[{ }^{3} \mathrm{H}\right]$ EMPA (Supplemental Fig. 5A) were determined by exposing the tracer-receptor complex to excess concentrations of OX1R-selective antagonist SB-334867 or unlabeled EMPA, respectively. Subsequently, the influence of increasing concentrations of lemborexant on the association kinetics of $\left[{ }^{125} \mathrm{I}\right]$ OXA to the hOX1R was assessed (Supplemental Fig. 4B). In a similar fashion, the effect of increasing concentrations of lemborexant, almorexant, and suvorexant on the association kinetics of $\left.{ }^{3} \mathrm{H}\right]$ EMPA to the hOX2R was determined (Supplemental Fig. 5, B-D, respectively).

Table 3 summarizes the kinetic parameters for labeled tracers and unlabeled DORAs on both human OXRs, as derived from data depicted in Supplemental Figs. 4 and 5. Lemborexant showed faster association to and dissociation from the hOX2R compared with suvorexant and almorexant, the kinetic profiles of which were consistent with what had previously been described (Gotter et al., 2013; Mould et al., 2014). Although the association speed of lemborexant to the hOX1R was comparable to that to the hOX2R, dissociation speed from the hOX1R was faster than from the hOX2R.

TABLE 1

$\mathrm{IC}_{50}$ and $K_{\mathrm{i}}$ values of lemborexant, almorexant, and suvorexant when competing against OXA on human, rat, and mouse OX1R and OX2R in RBA and a cell-based FDSS

Data represent the mean \pm S.E.M.

\begin{tabular}{|c|c|c|c|c|c|c|c|}
\hline & \multirow{2}{*}{\multicolumn{3}{|c|}{ RBA }} & \multicolumn{4}{|c|}{$\mathrm{FDSS} \mathrm{Ca}^{2+}$ Imaging Assay } \\
\hline & & & & \multirow{2}{*}{$\frac{\mathrm{EC}_{50}}{\mathrm{OXA}}$} & \multicolumn{3}{|c|}{$K_{\mathrm{i}}$} \\
\hline & Lemborexant & Almorexant & Suvorexant & & Lemborexant & Almorexant & Suvorexant \\
\hline & \multicolumn{3}{|c|}{$\mathrm{IC}_{50}$ in $10^{-9} \mathrm{~mol} / /$} & \multicolumn{4}{|c|}{$10^{-9} \mathrm{~mol} / \mathrm{l}$} \\
\hline hOX1R & $6.1 \pm 1.4$ & $8.6 \pm 6.5$ & $8.8 \pm 2.5$ & $1.32 \pm 0.22$ & $4.8 \pm 1.4$ & $7.0 \pm 1.2$ & $1.4 \pm 0.2$ \\
\hline hOX2R & $2.6 \pm 0.4$ & $4.6 \pm 1.6$ & $12.0 \pm 2.8$ & $0.89 \pm 0.14$ & $0.61 \pm 0.10$ & $2.6 \pm 0.3$ & $2.2 \pm 0.3$ \\
\hline rOX1R & N.D. & N.D. & N.D. & $0.39 \pm 0.11$ & $7.7 \pm 1.8$ & $8.6 \pm 2.3$ & $1.8 \pm 0.3$ \\
\hline rOX2R & N.D. & N.D. & N.D. & $0.50 \pm 0.20$ & $0.66 \pm 0.13$ & $3.6 \pm 1.0$ & $2.5 \pm 0.5$ \\
\hline mOX1R & N.D. & N.D. & N.D. & $0.92 \pm 0.11$ & $8.3 \pm 2.5$ & $10.2 \pm 2.2$ & $1.6 \pm 0.3$ \\
\hline mOX2R & N.D. & N.D. & N.D. & $1.04 \pm 0.10$ & $0.64 \pm 0.15$ & $2.9 \pm 0.6$ & $2.2 \pm 0.4$ \\
\hline
\end{tabular}

mOX1R, mouse OX1R; N.D., not determined; rOX1R, rat OX1R; rOX2R, rat OX2R. 
TABLE 2

$K_{\mathrm{i}}$ values and Schild slope values of lemborexant when competing against three orexin peptide agonists on human and mouse OX1R and OX2R in a cell-based functional reporter assay Data represent the mean \pm S.E.M.

\begin{tabular}{lcccc}
\hline & hOX1R & mOX1R & hOX2R & mOX2R \\
\hline$K_{\mathrm{i}}\left(10^{-9} \mathrm{~mol} / \mathrm{l}\right)$ & & & & \\
OXA & $14.1 \pm 3.1$ & $16.3 \pm 4.0$ & $0.39 \pm 0.08$ & $0.37 \pm 0.07$ \\
OXB & N.D. & N.D. & $0.58 \pm 0.13$ & $0.28 \pm 0.08$ \\
{$\left[\mathrm{Ala}^{11}, \mathrm{D}-\mathrm{Leu}^{15}\right.$ ]-OXB } & N.D. & N.D. & $0.42 \pm 0.05$ & $0.49 \pm 0.05$ \\
Schild Slope $^{\text {OXA }}$ & $1.08 \pm 0.05$ & $0.95 \pm 0.05$ & $1.00 \pm 0.02$ & $1.00 \pm 0.03$ \\
OXB & N.D. & N.D. & $0.93 \pm 0.02$ & $0.99 \pm 0.03$ \\
{$\left[\mathrm{Ala}^{11}, \mathrm{D}-L_{e u}{ }^{15}\right.$ ]-OXB } & N.D. & N.D. & $1.01 \pm 0.01$ & $1.03 \pm 0.02$ \\
\hline
\end{tabular}

mOX1R, mouse OX1R; N.D., not determined.

Off-Target Affinity Evaluation of Lemborexant. To detect the binding of lemborexant to targets other than OX2R and OX1R, a panel binding assay was conducted on 80 receptors, transporters, and ion channels of important physiologic function (High-Throughput Profile; CEREP), as well as eight additional drug dependence liability-related and sleep/wake regulation-related targets (CEREP).

Lemborexant did not interact in vitro with most targets considered to be involved in sleep/wake regulation, including binding sites for GABA and benzodiazepines on the GABA receptor, as well as receptors for prostaglandins D2 and E2, serotonin, noradrenaline, histamine, acetylcholine, dopamine, galanin, and corticotropin-releasing factor. Although no interaction with any target could be detected at $1 \mu \mathrm{mol} / \mathrm{l}$, significant binding ( $>50 \%$ inhibition) at $10 \mu \mathrm{mol} / /$ was observed only for the human MT1R (Supplemental Table 1).

To evaluate potential sleep-related effects on targets other than OXRs, a functional cell-based assay for interaction of lemborexant with human MT1R and MT2R was performed. There was no interaction with MT2R or any agonistic activity on MT1R up to $30 \mu \mathrm{mol} / \mathrm{l}$ (data not shown), but there was antagonistic activity of lemborexant on MT1R. Mechanistically, this could theoretically counteract the sleep-promoting action of the natural agonist melatonin, but the $K_{\mathrm{i}}$ values for human MT1R and hOX2R, as determined in cell-based functional assays, were 922 and $0.54 \mathrm{nmol} / \mathrm{l}$, respectively, indicating a multiple of about 1700 -fold. Therefore, the weak interaction of lemborexant with MT1R is not considered to be of physiologic relevance. For all other targets described above, the margin of $K_{\mathrm{i}}$ values compared with hOX2R was more than 18,000-fold.

Because almost all currently approved sleep medications have the $\mathrm{GABA}_{\mathrm{A}}$ receptor as their functional target, it was confirmed that no functional effect was observed when lemborexant was assayed at up to $5 \mu \mathrm{mol} / \mathrm{l}$ against recombinantly expressed human $\mathrm{GABA}_{\mathrm{A}}$ receptor in an electrophysiological patch-clamp assay. Positive control phenobarbital caused an increase in chloride ion current at concentrations of 50 and $100 \mu \mathrm{mol} / \mathrm{l}$.

Predicted Binding Models and Binding Free Energy. Representative three-dimensional structures from $30 \mathrm{~ns}$ MD simulation of lemborexant and hOX1R and hOX2R are shown in Fig. 2, $\mathrm{A}$ and $\mathrm{C}$, respectively, and two-dimensional interaction diagrams are depicted in Fig. 2, B and D, respectively. The OXR binding site for lemborexant was formed by transmembrane helices $2,3,5,6$, and 7 , and binding structure in both receptors was a U-shaped or horseshoe-like conformation with $\pi$-stacking between the 2,4-dimethylpyrimidine ring and the 5-fluoropyridine ring, which is also called "face-toface." In hOX1R, the 2,4-dimethylpyrimidine ring additionally formed a face-to-face $\pi-\pi$ interaction with HIS344 and a water bridge to TYR348, the $N$-(5-fluoropyridin-2-yl) group formed a hydrogen bond with GLN126, and the 3-fluorophenyl group was surrounded by several hydrophobic residues (ALA127, VAL130, TYR311, ILE314, and VAL347). When applying the same simulation to the hOX2R complex, the (2,4-dimethylpyrimidin5 -yl)oxy group formed this face-to-face $\pi-\pi$ interaction with HIS350 and two independent water bridges to THR111 and TYR354, the $N$-(5-fluoropyridin-2-yl) group formed a hydrogen bond with GLN134, and the 3-fluorophenyl group was surrounded by several hydrophobic residues (THR135, VAL138, TYR317, ILE320, and VAL353). Although the three aromatic rings in lemborexant were located in almost identical positions in both OXRs, slight differences in interaction pattern were recognized. Complete three-dimensional models (in PDB format) of lemborexant bound to the OXRs can be found in Supplemental Fig. 6 (hOX1R) and Supplemental Fig. 7 (hOX2R).

TABLE 3

Binding and dissociation kinetic parameters of radiolabeled tracers $\left(\left[{ }^{125} \mathrm{I}\right] \mathrm{OXA}\right.$ and $\left.\left[{ }^{3} \mathrm{H}\right] \mathrm{EMPA}\right)$ and nonlabeled test compounds $($ lemborexant, almorexant, and suvorexant) on human OXRs

Data represent the mean \pm S.E.M.

\begin{tabular}{|c|c|c|c|c|c|c|}
\hline & \multicolumn{2}{|c|}{ hOX1R } & \multicolumn{4}{|c|}{ hOX2R } \\
\hline & {$\left[{ }^{125} \mathrm{I}\right] \mathrm{OXA}$} & Lemborexant & {$\left[{ }^{3} \mathrm{H}\right] \mathrm{EMPA}$} & Lemborexant & Almorexant & Suvorexant \\
\hline $\mathrm{k}_{\mathrm{on}}{ }^{a}\left(\mathrm{l} \cdot \mathrm{nmol}^{-1} \cdot \min ^{-1}\right)$ & $0.0378 \pm 0.0106$ & $0.0262 \pm 0.0028$ & $0.0363 \pm 0.0008$ & $0.0496 \pm 0.0010$ & $0.0350 \pm 0.0014$ & $0.0052 \pm 0.0002$ \\
\hline
\end{tabular}

$\mathrm{k}_{\mathrm{off}}$, dissociation rate constant.

${ }^{a}$ Harmonic mean. 

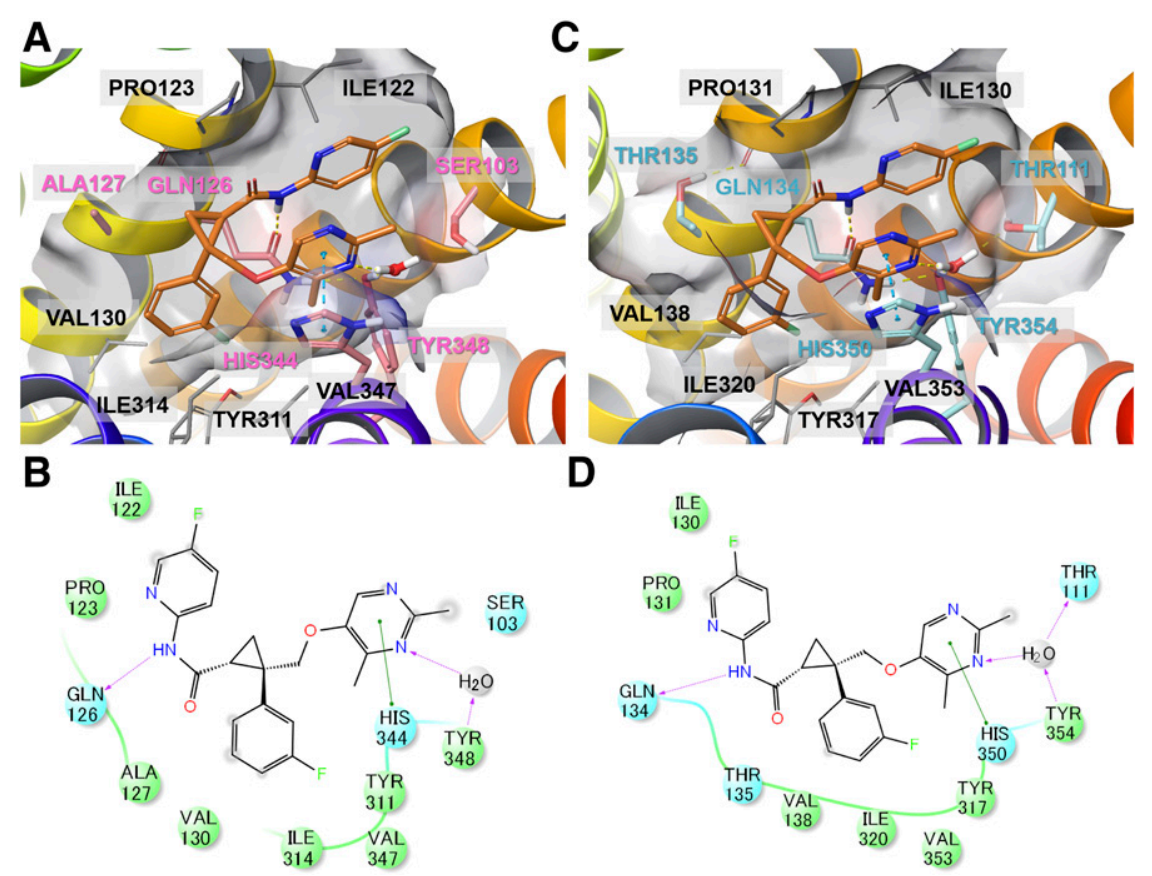

Fig. 2. Predicted binding locations of lemborexant in the orthosteric sites of hOX1R and hOX2R. The OXR residues found to be important for association with lemborexant are shown. (A) and (C) Three-dimensional structures. Lemborexant carbon atoms are shown as orange; differing residues in the orthosteric site between both receptors, as well as the carbon atoms of directly interacting and water-bridged protein residues are D shown as pink (A: hOX1R) and turquoise (C: hOX2R),

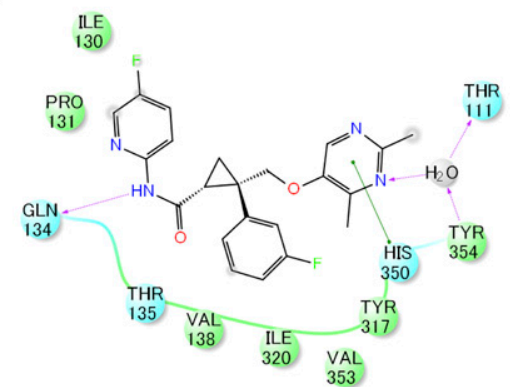
and other carbon atoms are shown as gray. Nitrogen atoms are colored blue, oxygen atoms red, and fluorine atoms green. Two-dimensional interaction diagrams of lemborexant with hOX1R (B) and hOX2R (D). Hydrophobic residues are shown as green, and hydrophilic residues are shown as light blue.

Binding free energy results using MM-GBSA are listed in Table 4. Van der Waals binding free energy had the major influence on binding affinity among all components; on the other hand, the contribution level of Coulomb energy was smaller than any other components such as lipophilicity and solvation factor. Binding free energy calculation results indicated that hydrophobic interactions in the ligand-receptor complex were the driving force for determining binding affinity and that the small Coulomb energy was related to few hydrogen bonds.

Binding conformation and formed interactions were similar between the hOX1R and hOX2R models; however, lemborexant binding affinity to the hOX2R was about $3 \mathrm{kcal} / \mathrm{mol}$ stronger than for the hOX1R.

\section{Discussion}

It has recently become clearer that insomnia is caused not so much by an inability of the brain to switch on sleep-related circuits but, rather, by the inability to switch off alertnessrelated circuits (Nofzinger, 2004; Nofzinger et al., 2004). Therefore, pharmacologically curbing these alertness-related internal factors could help in the treatment of insomnia. Rather than enhancing sleep drive in the way that $\mathrm{GABA}_{\mathrm{A}}$ receptor modulators or melatonin receptor agonists act,
DORAs counteract inappropriate wakefulness, thus offering potential advantages over therapy with the classic benzodiazepine and nonbenzodiazepine hypnotic agents and ramelteon (Borja and Daniel, 2006). As described above, the DORA lemborexant shows very promising in vitro characteristics as a potential insomnia medication.

Confirmed by a panel binding assay and follow-up cell-based functional assays, lemborexant shows very good selectivity for OX1R and OX2R compared with other targets.

Current thinking in the field is that to promote sleep in a fashion as close to natural sleep as possible, both non-REM and REM sleep times would need to be increased in insomnia treatment. Therefore, inhibiting both OXRs to a certain extent would be best (Morairty et al., 2012). Experiments on OX2R knockout mice and prepro-orexin knockout mice demonstrated that the OX2R is necessary for non-REM and REM sleep gating, whereas the OX1R is involved in REM sleep gating (Willie et al., 2003). We therefore hypothesized that the OX2R would be the main pharmacological target, whereas acknowledging that the inhibition of the OX1R would additionally be necessary. Consequently, lemborexant was designed to have a somewhat higher affinity for the OX2R over the OX1R (as demonstrated by RBA and two cell-based functional assays) (Tables 1 and 2) to have the potential for promoting both sleep types. It should also be noted that the

TABLE 4

Computational simulation results: Binding free energy and its components by prime MM-GBSA calculation

All energy values are in $\mathrm{kcal} / \mathrm{mol}$ and median score from trajectory of MD simulation.

\begin{tabular}{ccccccccc}
\hline Receptor & $\Delta G_{\text {bind }}$ & $\Delta G_{\text {Coul }}$ & $\Delta G_{\text {H-bond }}$ & $\Delta G_{\text {Cov }}$ & $\Delta G_{\text {vdW }}$ & $\Delta G_{\text {Lipo }}$ & $\Delta G_{\text {Packing }}$ & $\Delta G_{\text {Solv GB }}$ \\
\hline hOX1R & -55.100 & -11.715 & -0.626 & 0.215 & -43.335 & -19.237 & -3.002 & 23.774 \\
hOX2R & -58.173 & -12.254 & -0.577 & 0.372 & -44.357 & -21.723 & -2.892 & 22.676
\end{tabular}

$\Delta G_{\text {bind }}$, lemborexant receptor binding free energies; $\Delta G_{\mathrm{Coul}}$, the Coulomb binding free energy; $\Delta G_{\mathrm{Cov}}$, the covalent binding free energy; $\Delta G_{\mathrm{H} \text {-bond }}$, the hydrogen bonding free energy; $\Delta G_{\mathrm{Lipo}}$, the lipophilic binding free energy; $\Delta G_{\mathrm{Packing}}$, the $\pi-\pi$ packing free energy; $\Delta G_{\text {Solv GB }}$, the generalized Born solvation binding free energy; $\Delta G_{\mathrm{vdW}}$, the van der Waals binding free energy. 
2-SORA JNJ-42847922, which is now in clinical development, promotes non-REM sleep in rats without affecting REM sleep (Bonaventure at al., 2015). On the other hand, it was recently reported that the 2-SORA MK-1064 dose-dependently promoted both non-REM and REM sleep in rats (Stevens et al., 2016) as well as in phase 1 clinical studies in healthy volunteers (Struyk et al., 2015). It is still an ongoing discussion as to whether a DORA or 2-SORA would be better for the treatment of insomnia (Dugovic et al., 2009), and it will be very interesting to compare the future clinical data of DORAs and 2-SORAs to hopefully answer this question.

As indicated in Table 2, all Schild slopes are very close to 1, indicating competitive antagonism by lemborexant on every receptor evaluated. Schild slopes for lemborexant on OX2R do not differ among three different peptide agonists, suggesting orthosteric binding of the antagonist at the same site as the peptide agonists (Kenakin, 2004). Comparisons of $K_{\mathrm{i}}$ values and Schild slopes between human and mouse OXRs do not indicate a species difference in this assay. Taken together with the results of the direct intracellular $\mathrm{Ca}^{2+}$ imaging assay (Table 1), we could not detect any species difference in the antagonistic behavior of lemborexant among humans, rats, and mice. This is an important feature when considering mice and rats as preclinical sleep models for predicting the efficacy of lemborexant in humans.

The ideal requirements for the efficacy of a sleep drug are fast sleep onset, sufficient sleep maintenance throughout the night, and no problematic drug-related residual sleepiness the next morning. As the kinetic RBA data (Table 3) show, lemborexant binds quickly to and also dissociates quickly from the hOX1R and hOX2R, as a comparison of $k_{\text {on }}$ and $k_{\text {off }}$ values for successful drugs in the literature shows (Dahl and Akerud, 2013). These fast association and dissociation kinetic properties of lemborexant suggest that its pharmacodynamic effect will be driven by pharmacokinetic factors (i.e., plasma and brain concentration profiles), and that it therefore has the potential to fulfill the above-mentioned requirements on efficacy for a sleep drug by carefully adjusting dosage in clinical settings.

From the predicted molecular docking models, lemborexant showed a well-overlapped interaction within orthosteric binding sites of both human OXRs, which was similar to the conformation of suvorexant reported by others for binding to OX1R (Yin et al., 2016) and OX2R (Yin et al., 2015). Almost all interacting residues were the same in both receptors; however, the observation of a 2,4-dimethylpyrimidine ringTHR111 water bridge and THR135 involving hydrophobic pocket constituent residues were characteristic of the hOX2R interaction mode. In the comparison among components of binding free energy, the Coulomb, van der Waals, and lipophilic energy of the lemborexant/hOX2R binding model were scored slightly higher than those for the hOX1R complex. This increased interaction and the difference in binding free energy could qualitatively explain why lemborexant showed a higher affinity for or activity on hOX2R than for or on hOX1R in in vitro assays.

In conclusion, lemborexant demonstrated in multiple in vitro assays to be a high-affinity and very specific DORA with some preference for the OX2R. The in silico simulation of lemborexant binding to both OXRs is in agreement with these in vitro results. Furthermore, lemborexant displayed binding and dissociation kinetics desirable for an insomnia drug.
Lemborexant therefore possesses in vitro characteristics that indicate its potential as a future insomnia treatment and recommend it for further in vivo preclinical characterization.

\section{Acknowledgments}

The authors thank Kazuma Takase for molecular biological support with OXR-expressing in vitro systems, Ken Hatanaka for preparation of HEK293 cells stably expressing human GABA $_{A}$ receptor, Masahiro Bando for support with statistical analysis, as well as Yuka Ichigi and Mayumi Asano for excellent general technical support. We also thank Margaret Moline for critical review and comments on the manuscript and Yu Yoshida for help with Figure 1.

\section{Authorship Contributions}

Participated in research design: Beuckmann, Suzuki, Ueno, Nagaoka, Arai, Higashiyama.

Conducted experiments: Beuckmann, Suzuki, Ueno, Nagaoka, Arai, Higashiyama.

Performed data analysis: Beuckmann, Suzuki, Ueno, Nagaoka, Arai, Higashiyama.

Wrote or contributed to the writing of the manuscript: Beuckmann, Suzuki, Ueno, Nagaoka, Arai, Higashiyama.

\section{References}

Abel R, Young T, Farid R, Berne BJ, and Friesner RA (2008) Role of the active-site solvent in the thermodynamics of factor Xa ligand binding. J Am Chem Soc 130: 2817-2831.

Asahi S, Egashira S, Matsuda M, Iwaasa H, Kanatani A, Ohkubo M, Ihara M, and Morishima H (2003) Development of an orexin-2 receptor selective agonist, [Ala(11), D-Leu(15)]orexin-B. Bioorg Med Chem Lett 13:111-113.

Bettica P, Nucci G, Pyke C, Squassante L, Zamuner S, Ratti E, Gomeni R, and Alexander R (2012a) Phase I studies on the safety, tolerability, pharmacokinetics and pharmacodynamics of SB-649868, a novel dual orexin receptor antagonist. J Psychopharmacol 26:1058-1070.

Bettica P, Squassante L, Groeger JA, Gennery B, Winsky-Sommerer R, and Dijk DJ (2012b) Differential effects of a dual orexin receptor antagonist (SB-649868) and zolpidem on sleep initiation and consolidation, SWS, REM sleep, and EEG power spectra in a model of situational insomnia. Neuropsychopharmacology $\mathbf{3 7}$ : 1224-1233.

Bonaventure P, Shelton J, Yun S, Nepomuceno D, Sutton S, Aluisio L, Fraser I, Lord B, Shoblock J, Welty N, et al. (2015) Characterization of JNJ-42847922, a selective orexin-2 receptor antagonist, as a clinical candidate for the treatment of insomnia. J Pharmacol Exp Ther 354:471-482.

Borja NL and Daniel KL (2006) Ramelteon for the treatment of insomnia. Clin Ther 28:1540-1555.

Boutrel B, Kenny PJ, Specio SE, Martin-Fardon R, Markou A, Koob GF, and de Lecea L (2005) Role for hypocretin in mediating stress-induced reinstatement of cocaineseeking behavior. Proc Natl Acad Sci USA 102:19168-19173.

Brisbare-Roch C, Dingemanse J, Koberstein R, Hoever P, Aissaoui H, Flores S, Mueller C, Nayler O, van Gerven J, de Haas SL, et al. (2007) Promotion of sleep by targeting the orexin system in rats, dogs and humans. Nat Med 13:150-155.

Chemelli RM, Willie JT, Sinton CM, Elmquist JK, Scammell T, Lee C, Richardson JA, Williams SC, Xiong Y, Kisanuki Y, et al. (1999) Narcolepsy in orexin knockout mice: molecular genetics of sleep regulation. Cell 98:437-451.

Chen W, Shields TS, Stork PJS, and Cone RD (1995) A colorimetric assay for measuring activation of Gs- and Gq-coupled signaling pathways. Anal Biochem 226 349-354.

Coward P, Wada HG, Falk MS, Chan SDH, Meng F, Akil H, and Conklin BR (1998) Controlling signaling with a specifically designed Gi-coupled receptor. Proc Natl Acad Sci USA 95:352-357.

Cox CD, Breslin MJ, Whitman DB, Schreier JD, McGaughey GB, Bogusky MJ, Roecker AJ, Mercer SP, Bednar RA, Lemaire W, et al. (2010) Discovery of the dual orexin receptor antagonist [(7R)-4-(5-chloro-1,3-benzoxazol-2-yl)-7-methyl-1,4diazepan-1-yl] [5-methyl-2-(2H-1,2,3-triazol-2-yl)phenyl]methanone (MK-4305) for the treatment of insomnia. J Med Chem 53:5320-5332.

Dahl G and Akerud T (2013) Pharmacokinetics and the drug-target residence time concept. Drug Discov Today 18:697-707.

de Lecea L, Kilduff TS, Peyron C, Gao X, Foye PE, Danielson PE, Fukuhara C, Battenberg ELF, Gautvik VT, Bartlett FS, 2nd, et al. (1998) The hypocretins: hypothalamus-specific peptides with neuroexcitatory activity. Proc Natl Acad Sci USA 95:322-327.

Dowling MR and Charlton SJ (2006) Quantifying the association and dissociation rates of unlabelled antagonists at the muscarinic M3 receptor. $\mathrm{Br} J$ Pharmacol 148:927-937.

Dugovic C, Shelton JE, Aluisio LE, Fraser IC, Jiang X, Sutton SW, Bonaventure P, Yun S, Li X, Lord B, et al. (2009) Blockade of orexin-1 receptors attenuates orexin-2 receptor antagonism-induced sleep promotion in the rat. $J$ Pharmacol Exp Ther 330:142-151.

Durocher Y, Perret S, Thibaudeau E, Gaumond MH, Kamen A, Stocco R, and Abramovitz M (2000) A reporter gene assay for high-throughput screening of G-protein-coupled receptors stably or transiently expressed in HEK293 EBNA cells grown in suspension culture. Anal Biochem 284:316-326. 
Friesner RA, Banks JL, Murphy RB, Halgren TA, Klicic JJ, Mainz DT, Repasky MP, Knoll EH, Shelley M, Perry JK, et al. (2004) Glide: a new approach for rapid, accurate docking and scoring. 1. Method and assessment of docking accuracy. $J$ Med Chem 47:1739-1749.

Goto M, Yamada K, Katayama K, and Tanaka I (1996) Inhibitory effect of E3330, a novel quinone derivative able to suppress tumor necrosis factor-alpha generation, on activation of nuclear factor-kappa B. Mol Pharmacol 49:860-873.

Gotter AL, Winrow CJ, Brunner J, Garson SL, Fox SV, Binns J, Harrell CM, Cui D, Yee KL, Stiteler M, et al. (2013) The duration of sleep promoting efficacy by dual orexin receptor antagonists is dependent upon receptor occupancy threshold. BMC Neurosci 14:90.

Gotter AL, Forman MS, Harrell CM, Stevens J, Svetnik V, Yee KL, Li X, Roecker AJ, Fox SV, Tannenbaum PL, et al. (2016) Orexin 2 receptor antagonism is sufficient to promote NREM and REM sleep from mouse to man. Sci Rep 6:27147.

Halgren TA, Murphy RB, Friesner RA, Beard HS, Frye LL, Pollard WT, and Banks JL (2004) Glide: a new approach for rapid, accurate docking and scoring. 2. Enrichment factors in database screening. $J$ Med Chem 47:1750-1759.

Hara J, Beuckmann CT, Nambu T, Willie JT, Chemelli RM, Sinton CM, Sugiyama F, Yagami K, Goto K, Yanagisawa M, et al. (2001) Genetic ablation of orexin neurons in mice results in narcolepsy, hypophagia, and obesity. Neuron 30:345-354.

Harris GC, Wimmer M, and Aston-Jones G (2005) A role for lateral hypothalamic orexin neurons in reward seeking. Nature 437:556-559.

Herring WJ, Snyder E, Budd K, Hutzelmann J, Snavely D, Liu K, Lines C, Roth T, and Michelson D (2012) Orexin receptor antagonism for treatment of insomnia: a randomized clinical trial of suvorexant. Neurology 79:2265-2274.

Hollands EC, Dale TJ, Baxter AW, Meadows HJ, Powell AJ, Clare JJ, and Trezise DJ (2009) Population patch-clamp electrophysiology analysis of recombinant GABA $\alpha 1 \beta 3 \gamma 2$ channels expressed in HEK-293 cells. J Biomol Screen 14:769-780.

Huang N, Kalyanaraman C, Bernacki K, and Jacobson MP (2006) Molecular mechanics methods for predicting protein-ligand binding. Phys Chem Chem Phys 8 5166-5177.

Kenakin T (2004) Allosteric modulators: the new generation of receptor antagonist. Mol Interv 4:222-229.

Lin L, Faraco J, Li R, Kadotani H, Rogers W, Lin X, Qiu X, de Jong PJ, Nishino S, and Mignot $\mathrm{E}$ (1999) The sleep disorder canine narcolepsy is caused by a mutation in the hypocretin (orexin) receptor 2 gene. Cell 98:365-376.

Lyne PD, Lamb ML, and Saeh JC (2006) Accurate prediction of the relative potencies of members of a series of kinase inhibitors using molecular docking and MM-GBSA scoring. J Med Chem 49:4805-4808.

Marlo JE, Niswender CM, Days EL, Bridges TM, Xiang Y, Rodriguez AL, Shirey JK, Brady AE, Nalywajko T, Luo Q, et al. (2009) Discovery and characterization of novel allosteric potentiators of $\mathrm{M}_{1}$ muscarinic receptors reveals multiple modes of activity. Mol Pharmacol 75:577-588.

Morairty SR, Revel FG, Malherbe P, Moreau J-L, Valladao D, Wettstein JG, Kilduff TS, and Borroni E (2012) Dual hypocretin receptor antagonism is more effective for sleep promotion than antagonism of either receptor alone. PLoS One 7:e39131.

Motulsky HJ and Mahan LC (1984) The kinetics of competitive radioligand binding predicted by the law of mass action. Mol Pharmacol 25:1-9.

Mould R, Brown J, Marshall FH, and Langmead CJ (2014) Binding kinetics differentiates functional antagonism of orexin-2 receptor ligands. $B r J$ Pharmacol 171 351-363.

Nofzinger EA (2004) What can neuroimaging findings tell us about sleep disorders? Sleep Med 5 (Suppl 1):S16-S22.

Nofzinger EA, Buysse DJ, Germain A, Price JC, Miewald JM, and Kupfer DJ (2004) Functional neuroimaging evidence for hyperarousal in insomnia. Am J Psychiatry 161:2126-2128.
Roecker AJ, Mercer SP, Schreier JD, Cox CD, Fraley ME, Steen JT, Lemaire W, Bruno JG, Harrell CM, Garson SL, et al. (2014) Discovery of $5^{\prime \prime}$-chloro-N-[(5,6 dimethoxypyridin-2-yl)methyl]-2,2':5',3' -terpyridine-3'-carboxamide (MK-1064): a selective orexin 2 receptor antagonist (2-SORA) for the treatment of insomnia. ChemMedChem 9:311-322.

Sakurai T, Amemiya A, Ishii M, Matsuzaki I, Chemelli RM, Tanaka H, Williams SC, Richardson JA, Kozlowski GP, Wilson S, et al. (1998) Orexins and orexin receptors: a family of hypothalamic neuropeptides and $G$ protein-coupled receptors that regulate feeding behavior. Cell 92:573-585.

Sakurai T (2007) The neural circuit of orexin (hypocretin): maintaining sleep and wakefulness. Nat Rev Neurosci 8:171-181.

Stevens J, Gotter AL, Garson SL, Fox SV, Svetnik V, Tannenbaum PL, Forman MS Coleman PJ, Herring WJ, Renger JJ, et al. (2016) REM promotion by dual and orexin 2 receptor antagonists relative to standard of care across mammals. Sleep 39 (Suppl 1):A222.

Struyk A, Ma J, Li X, Winrow C, Herring WJ, Zappacosta P, Renger J, and Forman M (2015) A polysomnographic study of sleep effects of MK-1064, a selective orexin-2 receptor antagonist, in healthy individuals. Sleep 38 (Suppl 1):A233.

Willie JT, Chemelli RM, Sinton CM, Tokita S, Williams SC, Kisanuki YY, Marcus JN, Lee C, Elmquist JK, Kohlmeier KA, et al. (2003) Distinct narcolepsy syndromes in Orexin receptor-2 and Orexin null mice: molecular genetic dissection of non-REM and REM sleep regulatory processes. Neuron 38:715-730.

Winrow CJ, Gotter AL, Cox CD, Doran SM, Tannenbaum PL, Breslin MJ, Garson SL Fox SV, Harrell CM, Stevens J, et al. (2011) Promotion of sleep by suvorexant-a novel dual orexin receptor antagonist. J Neurogenet 25:52-61.

Winrow CJ, Gotter AL, Cox CD, Tannenbaum PL, Garson SL, Doran SM, Breslin MJ, Schreier JD, Fox SV, Harrell CM, et al. (2012) Pharmacological characterization of MK-6096-a dual orexin receptor antagonist for insomnia. Neuropharmacology 62: 978-987.

Yamanaka A, Beuckmann CT, Willie JT, Hara J, Tsujino N, Mieda M, Tominaga M, Yagami Ki, Sugiyama F, Goto K, et al. (2003) Hypothalamic orexin neurons regulate arousal according to energy balance in mice. Neuron 38:701-713.

Yin J, Mobarec JC, Kolb P, and Rosenbaum DM (2015) Crystal structure of the human $\mathrm{OX}_{2}$ orexin receptor bound to the insomnia drug suvorexant. Nature $\mathbf{5 1 9}$ $247-250$.

Yin J, Babaoglu K, Brautigam CA, Clark L, Shao Z, Scheuermann TH, Harrell CM, Gotter AL, Roecker AJ, Winrow CJ, et al. (2016) Structure and ligand-binding mechanism of the human $\mathrm{OX}_{1}$ and $\mathrm{OX}_{2}$ orexin receptors. Nat Struct Mol Biol 23: 293-299.

Yoshida Y, Terauchi T, Naoe Y, Kazuta Y, Ozaki F, Beuckmann CT, Nakagawa M, Suzuki M, Kushida I, Takenaka O, et al. (2014) Design, synthesis, and structureactivity relationships of a series of novel $\mathrm{N}$-aryl-2-phenylcyclopropanecarboxamide that are potent and orally active orexin receptor antagonists. Bioorg Med Chem 22 : $6071-6088$.

Yoshida Y, Naoe Y, Terauchi T, Ozaki F, Doko T, Takemura A, Tanaka T, Sorimachi K, Beuckmann CT, Suzuki M, et al. (2015) Discovery of (1R,2S)-2-\{[(2,4-dimethylpyrimidin5-yl)oxy]methyl\}-2-(3-fluorophenyl)-N-(5-fluoropyridin-2-yl)cyclopropanecarboxamide (E2006): a potent and efficacious oral orexin receptor antagonist. $J$ Med Chem 58: 4648-4664.

Address correspondence to: Carsten Theodor Beuckmann, Neurology Business Group, Discovery, Tsukuba Research Laboratories, Eisai Co., Ltd., 5-1-3 Tokodai, Tsukuba, Ibaraki 300-2635, Japan. E-mail: c-beuckmann@hhc. eisai.co.jp 